\title{
Monitoria como espaço de iniciação à docência
}

\author{
Monitorship as a teaching initiation space \\ El seguimiento como espacio de iniciación docente
}

Jéssica Tâmara do Nascimento ${ }^{1 *}$, Letícia Tereza da Silva Cardoso¹, Linda Concita Nunes Araújo², Vandreza Valéria do Nascimento Oliveira1, Esvaldo dos Santos Silva ${ }^{1}$, Paulo Jorge Torres Guimarães Silva ${ }^{3}$, José Weslley Feitoza Santos Clemente ${ }^{4}$.

\section{RESUMO}

Objetivo: Relacionar a monitoria como espaço de iniciação a docência. Métodos: Revisão integrativa da literatura elaborada a partir da coleta de dados de fontes secundárias e levantamento bibliográfico realizada através das seguintes bases de dados: Literatura Latino-Americana e do Caribe em Ciências da Saúde (LILACS), Scientific Eletronic Library Online (SciELO) e Base de Dados de Enfermagem (BDENF). Resultados: Como amostra final foram selecionados 10 artigos a serem utilizados na realização deste estudo. Constatou-se que ao atuar como monitor o aluno cria oportunidades e se destaca no meio acadêmico devido à riqueza dos conhecimentos e experiências adquiridas, a monitoria se configura como importante atividade realizada durante a graduação, além de ser uma forma alternativa de trabalho pedagógico. Considerações finais: Foi notória a falta de estudos publicados a respeito da temática, o que denota a falta de estímulo, vagas, ou interesse dos discentes a programas como a monitoria durante a graduação. Ser monitor permite ao discente enxergar uma área de atuação além da assistência, oferecendo-lhe uma visão holística sobre atuar no âmbito de multiplicador de conhecimento além de introduzi-lo nas formas e métodos didáticos que é de suma importância para a atuação do enfermeiro em diversas áreas.

Palavras-chave: Monitoria, Ensino, Aprendizagem.

\begin{abstract}
Objective: To link monitoring as a teaching initiation space. Methods: Integrative literature review based on data collection from secondary sources and bibliographic survey carried out through the following databases: Latin American and Caribbean Health Sciences Literature (LILACS), Scientific Electronic Library Online (SciELO) and Nursing Database (BDENF). Results: As a final sample, 10 articles were selected to be used in this study. It was found that when acting as a monitor the student creates opportunities and stands out in the academic environment due to the wealth of knowledge and experiences acquired, the monitoring is configured as an important activity performed during graduation, in addition to being an alternative form of pedagogical work. Final considerations: There was a notable lack of published studies on the theme, which denotes the lack of encouragement, vacancies, or interest of students in programs such as monitoring during graduation. Being a monitor allows the student to see an area of performance beyond assistance, offering a holistic view of acting in the context of knowledge multiplier, in addition to introducing it in the forms and didactic methods that are of paramount importance for the performance of nurses in several areas.
\end{abstract}

Keywords: Monitoring, Teaching, Learning.

\section{RESUMEN}

Objetivo: Vincular la monitorización como espacio de iniciación docente. Métodos: Revisión bibliográfica integradora basada en la recolección de datos de fuentes secundarias y levantamiento bibliográfico realizado a través de las siguientes bases de datos: Literatura Latinoamericana y del Caribe en Ciencias de la Salud (LILACS), Biblioteca Electrónica Científica en Línea (SciELO) y Base de datos de enfermería (BDENF). Resultados: Como muestra final, se seleccionaron 10 artículos para ser utilizados en este estudio. Se encontró que al actuar como monitor el alumno genera oportunidades y se destaca en el ámbito académico por la riqueza de conocimientos y experiencias adquiridas, el seguimiento se configura como una actividad importante que se realiza durante la graduación, además de ser una forma alternativa de trabajo pedagógico. Consideraciones finales: Destaca la falta de estudios publicados sobre el tema, lo que denota la falta de estímulo, vacantes o interés de los estudiantes en programas como el seguimiento durante la graduación. Ser monitor permite al alumno ver un área de actuación más allá de la asistencia, ofreciendo una visión holística del actuar en el contexto del conocimiento multiplicador, además de introducirlo en las formas y métodos didácticos que son de suma importancia para el desempeño del enfermero en varias áreas. áreas.

Palabras clave: Supervisión, Enseñando, Aprendizaje.

${ }^{1}$ Faculdade Estácio de Alagoas (FAL), Maceió - AL. *E-mail: jessicanascimento.al@gmail.com

2 Universidade Federal da Bahia (UFBA), Salvador - BA.

3 Universidade de Brasília (UNB), Brasília - DF.

${ }^{4}$ Universidade Estadual de Ciências da Saúde de Alagoas (UNCISAL), Maceió - AL.

SUBMETIDO EM: 10/2020 


\section{INTRODUÇÃO}

O profissional de enfermagem possui inúmeras possibilidades e áreas de especialização, como a atenção básica, enfermagem do trabalho, saúde mental, geriatria, pesquisa e docência. Os enfermeiros compõem $20 \%$ do quadro da equipe de enfermagem, no que diz respeito ao mundo do trabalho $59,3 \%$ das equipes encontram-se no setor público, 31,8\% no privado, 14,6\% no filantrópico e 8,2\% nas atividades de ensino (FIOCRUZ; 2015). Tornar-se docente no ensino superior requer mais que desenvolver habilidades profissionais, é um processo gradual que envolve experiências profissionais vividas, ressignificações particulares, confirmadas a partir de situações presenciadas, situações essas que vão além das competências exigidas para um bom enfermeiro (LIMA PG e SANTOS PLF, 2016).

A monitoria foi instituída no Brasil pela lei no 5.540 de 28 de novembro de 1968 que fala sobre as Diretrizes e bases curriculares da Educação Nacional e que posteriormente foi revogada pela lei no 9.394 de 20 de Dezembro de 1996 (BRASIL, 2005). Sua prática possibilita aprendizado mútuo, ou seja, tanto o monitor quanto o discente monitorado participam do processo de ensino e aprendizagem, pois o monitor ao compartilhar seus conhecimentos reafirma e consolida tudo o que foi aprendido por ele na disciplina e o discente monitorado fixa o conteúdo recentemente aprendido, tira dúvidas e pratica (FIGUEIREDO TC, et al., 2016).

Dentre algumas atividades que compõem a formação curricular do enfermeiro no ensino e pesquisa, a monitoria é uma prática que tem como algumas de suas finalidades aprofundar, disseminar conhecimentos, desenvolver competências e habilidades didático pedagógicas da profissão docente, contribuindo assim, para a qualidade do ensino prestado na graduação. Ela surge também como um serviço de apoio pedagógico que visa aprofundar conhecimentos e solucionar as diversas dificuldades do discente acerca da disciplina cursada na graduação (LIRA MO, et al., 2015).

A formação do profissional docente não pode ser vista apenas do ponto de vista técnico, ela deve vincular teoria, prática e aspectos intrínsecos a futura realidade de atuação, pois a prática docente está inserida em todas as demais áreas da enfermagem, pois para desenvolver a sistematização ou qualquer outra assistência ao cliente se faz necessário ter pelo menos um conhecimento básico sobre docência e suas técnicas de troca de conhecimentos (NASCIMENTO F, 2016). Sabemos que tecnicamente o primeiro contato com a prática docente se dá através dos programas de stricto sensu e lato sensu, mesmo que de forma ainda muito superficial. Logo, porque não incluir disciplinas de práticas pedagógicas e/ou iniciação à docência na matriz curricular da graduação em enfermagem, já que essa é uma área em expansão e irá contribuir para o processo de aprendizagem e qualificação do discente?

Nesse contexto, a graduação não capacita o estudante a atuar como professor, mas para o exercício profissional que envolve questões relativas à prática laboral comum (TREVISO $P$ e COSTA BEP, 2017). $O$ ensino superior em Enfermagem tem essa característica, porém, a necessidade do mundo do trabalho, a aptidão, a casualidade, o prazer ou a remuneração, são fatores que podem justificar o aumento do número de profissionais enfermeiros atuando como professores.

Entretanto, de acordo com as Diretrizes Curriculares Nacionais do Curso de Graduação em Enfermagem (2001), o enfermeiro deve estar apto a desenvolver ações de promoção e prevenção à saúde. Ações essas que necessitam da didática para promover o aprendizado, visando introduzir o cliente no método de ensino e tirando do enfermeiro o papel de único detentor do saber, propiciando ao cliente uma maior autonomia para promover o autocuidado.

O enfermeiro também deve ser capaz de aprender a aprender e se comprometer com o treinamento e educação continuada de sua equipe, a fim de ofertar um atendimento responsável, de qualidade e sistematizado. É de suma importância que ainda durante a graduação o futuro enfermeiro se perceba como protagonista do seu processo de formação o que vai auxilia-lo em sua futura carreira profissional e enriquecer seu currículo durante a graduação. A introdução de disciplinas para a capacitação pedagógica do enfermeiro durante a graduação, além de estimular novas competências despertam o desenvolvimento intelectual do futuro profissional de enfermagem (BRASIL, 2001).

Exercer a enfermagem requer do profissional uma fundamentação técnico-cientifica com alicerce nos princípios éticos da profissão, por isso, o ensino superior contribui decisivamente para a construção do 
conhecimento, habilidades, aprendizagem e comprometimento necessários a qualquer profissional de enfermagem, o que torna a monitoria acadêmica durante a graduação uma ferramenta de extrema importância e relevância para os discentes, pois além de despertar o interesse do acadêmico na atuação docente a monitoria acaba desenvolvendo neste, técnicas de aperfeiçoamento do ensino (ANDRADE EGR, et al., 2018).

Durante a graduação dos cursos na área da saúde dentre eles a enfermagem, percebe-se um déficit ao estímulo à docência por parte das instituições, causando uma lacuna na formação de profissionais capacitados e hábeis para atividades que requerem um mínimo de conhecimento dessa modalidade, por isso necessita-se formar profissionais pautados no desenvolvimento dessa atividade. Sendo o contato com a docência ofertado a partir dos aspectos pedagógicos indiretos que permeiam as monitorias e os projetos de extensão. Estudos mostram que os egressos entram na docência pela necessidade do mundo do trabalho ou pelo retorno financeiro oriundo desta atividade, sendo necessário, porém, buscar outras qualificações para sua atuação devido à falta de subsídios e ferramentas metodológicas que permeiam o seu processo de formação (TREVISO P e COSTA BEP, 2017).

Segundo a Lei das Diretrizes e Bases da Educação Nacional no 9.394, de 20 de Dezembro de 1996, no Art. 84 "Os discentes da educação superior poderão ser aproveitados em tarefas de ensino e pesquisa pelas respectivas instituições, exercendo funções de monitoria, de acordo com seu rendimento e seu plano de estudos". A monitoria é uma modalidade de ensino que além de contribuir para a aprendizagem e formação do aluno o introduz nas atividades de pesquisa, ensino e extensão dos cursos de graduação. É também, uma oportunidade para que o aluno coloque em prática os conhecimentos adquiridos com a disciplina cursada, revise e fixe o conteúdo aprendido em sala de aula, aprimore seus saberes e fortaleça a implementação das habilidades relacionadas ao papel do docente como comunicação, desenvoltura, flexibilidade e raciocínio crítico (VICENZI CB, et al., 2016).

O interesse do estudo emergiu após o ingresso das discentes nos programas de extensão da instituição e após a leitura de artigos e apresentação de trabalhos voltados a formação docente, percebendo que durante a graduação, há lacunas que não estimulam o discente a adentrar na área do ensino, as discentes acharam necessária a elaboração de um estudo voltado a esta temática a fim de tentar fortalecer pesquisas e possibilitar uma maior abrangência nesta área de atuação.

A relevância do estudo se dá pela percepção de que a monitoria é uma atividade que engloba aprendizado, compartilhamento de experiências, desenvolvimento individual e/ou grupo, em que o monitor, o aluno monitorado e o professor orientador participam ativamente do processo de ensino-aprendizagem. Por fim, o estudo teve a seguinte questão norteadora: quais as evidências cientificas que relacionam a monitoria como espaço de iniciação à docência? O estudo teve como objetivo analisar as evidências cientifica que relacionam a monitoria como espaço de iniciação à docência.

\section{MÉTODOS}

O estudo consiste em uma revisão integrativa da literatura e foi elaborado a partir da coleta de dados de fontes secundárias e levantamento bibliográfico. Diante disso, a coleta dos dados foi realizada nas seguintes bases de dados: (LILACS), (SciELO), e (BDENF). Foram utilizados os descritores/palavra-chave: "monitoria", "ensino" e "aprendizagem", ressaltando que o descritor "monitoria" teve a particularidade de ser utilizado mesmo não sendo cadastrado na base dos Descritores em Ciências da Saúde - DECs, porém foi incluso aos meios de busca devido estar relacionado ao tema do estudo em questão.

Na primeira etapa do estudo, foi estabelecida a identificação do tema "Monitoria como espaço de iniciação à docência" e realizada a escolha da questão norteadora, que foi "quais as evidencias cientificas que relacionam a monitoria como espaço de iniciação à docência?". Na segunda etapa foram estabelecidos os critérios de inclusão, em que adotou-se: artigos originais na íntegra disponíveis na forma online e gratuita sobre o tema proposto; artigos publicados em português e inglês sem restrição de ano devido à baixa produção científica acerca da temática abordada.

Como critérios de exclusão foram utilizados: capítulos de livros, teses, dissertações, monografias, resenhas, manuais, artigos incompletos, artigos que não respondam à questão de pesquisa e os estudos duplicados. Os estudos encontrados em mais de uma base de dados serão considerados somente uma vez. 
Buscou-se estabelecer o mínimo de critérios que pudesse restringir busca, a fim de abranger o maior número de artigos possíveis. A busca pelos artigos foi realizada diretamente nas bases de dados LILACS, BDENF e SCIELO com a utilização dos descritores mencionados anteriormente (Tabela 1).

Tabela 1 - Trajetória metodológica.

\begin{tabular}{clccc}
\hline № & Estratégia de busca & LILACS & BDENF & SCIELO \\
\hline 1 & Monitoria AND aprendizagem AND ensino & 17 & 13 & 6 \\
2 & Monitoria AND aprendizagem & 23 & 13 & 10 \\
3 & Monitoria AND ensino & 48 & 22 & 17 \\
4 & Total por base: & 88 & 48 & 33 \\
\hline 5 & Total geral: & & 169 & \\
\hline
\end{tabular}

Fonte: Nascimento JT, et al., 2020.

$\mathrm{Na}$ terceira etapa definiram-se as informações a serem extraídas dos trabalhos selecionados, a quarta etapa foi composta pela avaliação dos trabalhos selecionados. Embora a monitoria beneficie tanto ao discente, instituição de ensino e ao docente, encontrar estudos que abordassem a temática foi dificultoso, o que evidencia a necessidade de investir em pesquisas de campo para essa área.

Durante a quinta etapa realizou-se a interpretação e discussão dos principais resultados da pesquisa, o que possibilitou uma análise crítica percepção dos problemas e/ou soluções, pontos positivos e identificação das lacunas presentes. E por fim, na sexta e última etapa serão apresentadas sínteses dos conhecimentos adquiridos que foram abordados neste estudo.

\section{RESULTADOS}

De acordo com a estratégia de busca foram encontrados 169 artigos, sendo disponíveis 139 artigos, decorreu-se a leitura dos títulos onde foram excluídos 101 artigos restando 38 estudos. Após a leitura do resumo, foram excluídos 09 estudos, procedeu-se então para a leitura do texto na integra que resultou na escolha de 14 artigos, após a leitura completa dos 14 artigos foi feita a exclusão de mais 04 artigos por não corresponderem com o tema abordado em nosso estudo, para participar da amostra final foram selecionados 10 artigos a serem utilizados na realização deste estudo (Gráfico 1).

Gráfico 1 - Estratégia de busca da quantidade dos artigos selecionados de acordo com as bases de dados utilizadas.

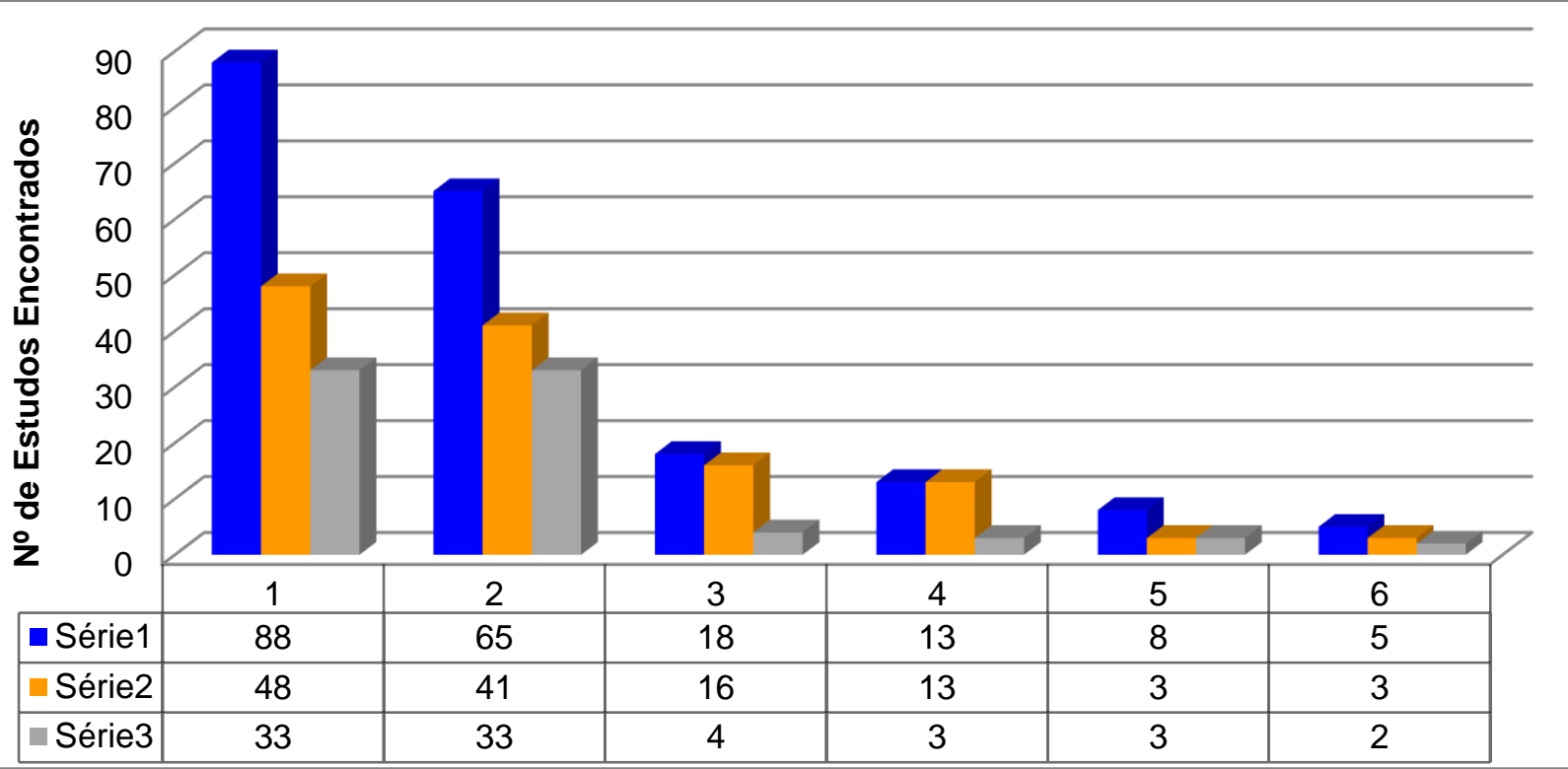

Fonte: Nascimento JT, et al., 2020.

Para melhor compreensão, análise e apresentação dos resultados, elaborou-se um quadro com dados contendo os Títulos dos Artigos / Autores / Periódicos / Ano de Publicação; Base de Dados; Objetivos; Metodologia/Tipo de Estudo e Conclusão (Quadro 1). 
Quadro1 - Apresentação da síntese dos artigos incluídos na revisão.

\begin{tabular}{|c|c|c|c|c|c|}
\hline № & $\begin{array}{l}\text { Título do Artigo/Autores/Periódico } \\
\text { /Ano de Publicação }\end{array}$ & $\begin{array}{l}\text { Base de } \\
\text { Dados }\end{array}$ & Objetivos & Metodologia / Tipo de Estudo & Conclusão \\
\hline 1 & $\begin{array}{l}\text { Contribuições da monitoria no } \\
\text { processo ensino-aprendizagem em } \\
\text { enfermagem / Haag et al. / Revista } \\
\text { Brasileira de Enfermagem / } 2007 \text {. }\end{array}$ & SCIELO & $\begin{array}{l}\text { Investigar a percepção do aluno e } \\
\text { professor em relação à prática de } \\
\text { monitoria e a influência desta no } \\
\text { desenvolvimento das atividades de } \\
\text { estágio. }\end{array}$ & $\begin{array}{l}\text { Estudo do tipo descritivo com } \\
\text { abordagem quantitativa. }\end{array}$ & $\begin{array}{l}\text { A partir deste estudo, evidencia-se a } \\
\text { importância da prática de monitoria pelos } \\
\text { alunos do curso de Enfermagem. }\end{array}$ \\
\hline 2 & $\begin{array}{l}\text { Monitoria: fonte de saberes à docência } \\
\text { superior / Dantas, O. M./ Rev. bras. } \\
\text { Estud. pedagog. / } 2014 \text {. }\end{array}$ & SCIELO & $\begin{array}{l}\text { Delinear as concepções de duas } \\
\text { universidades públicas federais sobre o } \\
\text { papel e a importância da monitoria para } \\
\text { a docência superior no que tange à } \\
\text { letra da lei e à visão de alguns } \\
\text { professores e alunos. }\end{array}$ & $\begin{array}{l}\text { Pesquisa de campo: em que } \\
\text { foram analisados projetos de } \\
\text { ensino, entrevistas, dados } \\
\text { estatísticos de distribuição de } \\
\text { bolsas e legislações da } \\
\text { Universidade Federal do Rio } \\
\text { Grande do Norte (UFRN) e da } \\
\text { Universidade de Brasília (UnB). }\end{array}$ & $\begin{array}{l}\text { A monitoria é de suma importância como } \\
\text { apoio à melhoria da qualidade do ensino } \\
\text { na UFRN e na UnB e engloba as } \\
\text { potencialidades do cursista, } \\
\text { constituindo-se em uma atividade plena, } \\
\text { pois auxilia a expansão dos saberes } \\
\text { pedagógicos produzidos durante sua } \\
\text { formação profissional, bem como da } \\
\text { criatividade, da pesquisa, da } \\
\text { autoexpressão, do raciocínio, da } \\
\text { compreensão e da sensibilidade didático } \\
\text { pedagógica na relação com o outro } \\
\text { (orientador ou colega). }\end{array}$ \\
\hline 3 & $\begin{array}{l}\text { A monitoria acadêmica na percepção } \\
\text { dos graduandos de enfermagem / } \\
\text { Abreu et al. / Rev enferm UERJ / } 2014 \text {. }\end{array}$ & LILACS & $\begin{array}{l}\text { Conhecer os motivos da procura pela } \\
\text { monitoria acadêmica; descrever a } \\
\text { vivência dos graduandos nesta } \\
\text { atividade e analisar suas contribuições } \\
\text { para a formação dos estudantes de } \\
\text { enfermagem. }\end{array}$ & $\begin{array}{l}\text { Estudo descritivo com } \\
\text { abordagem quantiqualitativa }\end{array}$ & $\begin{array}{l}\text { Este estudo descreveu a percepção dos } \\
\text { graduandos de enfermagem acerca da } \\
\text { monitoria acadêmica, permitindo } \\
\text { desvelar a importância desta atividade } \\
\text { na formação dos jovens. }\end{array}$ \\
\hline 4 & $\begin{array}{l}\text { A monitoria de educação em saúde na } \\
\text { enfermagem: relato de experiência / } \\
\text { Barbosa et al. / Revista de } \\
\text { enfermagem UFPE / } 2017 \text {. }\end{array}$ & BDENF & $\begin{array}{l}\text { Relatar as experiências de monitoria } \\
\text { vivenciadas junto à disciplina de } \\
\text { Educação em Saúde na Enfermagem, } \\
\text { segundo a percepção do acadêmico } \\
\text { monitor. Descrever a contribuição da } \\
\text { monitoria para a formação profissional. }\end{array}$ & Estudo descritivo & $\begin{array}{l}\text { A monitoria junto à disciplina de } \\
\text { Educação em Saúde na Enfermagem } \\
\text { representa uma oportunidade para que o } \\
\text { monitor aproxime saberes teóricos e } \\
\text { práticos, fundamentando-se em relações } \\
\text { de troca entre os próprios colegas, com } \\
\text { os docentes e com a comunidade. }\end{array}$ \\
\hline
\end{tabular}




\begin{tabular}{|c|c|c|c|c|c|}
\hline № & $\begin{array}{l}\text { Título do Artigo/Autores/Periódico } \\
\text { /Ano de Publicação }\end{array}$ & $\begin{array}{l}\text { Base de } \\
\text { Dados }\end{array}$ & Objetivos & Metodologia / Tipo de Estudo & Conclusão \\
\hline 5 & $\begin{array}{l}\text { Habilidades e dificuldades técnico- } \\
\text { científicas dos acadêmicos de } \\
\text { enfermagem durante a monitoria de } \\
\text { semiotécnica / Maran et al./ Rev } \\
\text { enferm UFPE / } 2017 .\end{array}$ & BDENF & $\begin{array}{l}\text { Descrever as habilidades e dificuldades } \\
\text { técnico-científicas dos acadêmicos de } \\
\text { Enfermagem durante a monitoria de } \\
\text { Semiotécnica. }\end{array}$ & $\begin{array}{l}\text { Estudo descritivo, } \quad \text { com } \\
\text { abordagem quantitativa. }\end{array}$ & $\begin{array}{l}\text { A monitoria oportunizou ao aluno o } \\
\text { aperfeiçoamento das técnicas, } \\
\text { habilidades para o exercício profissional, } \\
\text { aprendizagem interativa, reflexão } \\
\text { baseada na problematização e } \\
\text { reconstrução do saber. }\end{array}$ \\
\hline 6 & $\begin{array}{l}\text { Monitoria acadêmica e o cuidado da } \\
\text { pessoa com estomia: relato de } \\
\text { experiência / Fernandes et al. / Rev } \\
\text { Min Enferm. } 2015 \text {. }\end{array}$ & LILACS & $\begin{array}{l}\text { Relatar uma experiência de monitoria } \\
\text { do curso de graduação em } \\
\text { Enfermagem com uma equipe de } \\
\text { monitores que foi composta de cinco } \\
\text { estudantes sobre o processo de cuidar } \\
\text { no período pré-operatório de cirurgia } \\
\text { geradora de estomia. }\end{array}$ & $\begin{array}{l}\text { Estudo descritivo, tipo relato de } \\
\text { experiência. }\end{array}$ & $\begin{array}{l}\text { As atividades desenvolvidas na monitoria } \\
\text { impulsionam o aprendizado dos demais } \\
\text { estudantes sob a responsabilidade } \\
\text { docente e, principalmente, as ações de } \\
\text { educação em saúde frente ao processo } \\
\text { de reabilitação de pessoas com estomia. }\end{array}$ \\
\hline 7 & $\begin{array}{l}\text { Monitoria acadêmica na formação } \\
\text { em/para a saúde: desafios e } \\
\text { possibilidades no âmbito de um } \\
\text { currículo inter profissional em saúde / } \\
\text { Santos; Batista/ ABCS HEALTH } \\
\text { SCIENCES / 2015. }\end{array}$ & LILACS & $\begin{array}{l}\text { Discutir a monitoria desenvolvida na } \\
\text { Universidade Federal de São Paulo } \\
\text { (UNIFESP), Campus Baixada Santista, } \\
\text { como potencial espaço de formação } \\
\text { em/para a saúde a partir das } \\
\text { percepções dos discentes sobre a } \\
\text { experiência de ser monitor dentro da } \\
\text { proposta de um currículo } \\
\text { interdisciplinar e interprofissional. }\end{array}$ & $\begin{array}{l}\text { Pesquisa De Campo: com dados } \\
\text { produzidos a partir da aplicação } \\
\text { de questionário à } 41 \text { monitores e } \\
\text { submetidos à análise de } \\
\text { conteúdo do tipo temática. }\end{array}$ & $\begin{array}{l}\text { O estudante que se predispõe a } \\
\text { desempenhar a função de monitor dentro } \\
\text { da proposta curricular do Campus } \\
\text { Baixada Santista se depara com } \\
\text { situações que o preparam para a prática } \\
\text { em saúde na perspectiva da } \\
\text { interprofissionalidade, da diversidade, do } \\
\text { trabalho em equipe e da troca de } \\
\text { saberes. }\end{array}$ \\
\hline 8 & $\begin{array}{l}\text { Monitoria em semiologia e } \\
\text { semiotécnica para a enfermagem: um } \\
\text { relato de experiência / Carvalho et al. / } \\
\text { Rev Enferm UFSM / } 2012 \text {. }\end{array}$ & BDENF & $\begin{array}{l}\text { Relatar a experiência de acadêmicos } \\
\text { de enfermagem no desempenho de } \\
\text { suas atividades de monitoria na } \\
\text { disciplina semiologia e semiotécnica } \\
\text { para enfermagem em uma instituição } \\
\text { de ensino superior da cidade de Natal, } \\
\text { Rio Grande do Norte, no período } \\
\text { compreendido entre os meses de } \\
\text { setembro de } 2009 \text { a setembro de } 2010 \text {. }\end{array}$ & $\begin{array}{l}\text { Pesquisa de Campo: realizada } \\
\text { no laboratório de enfermagem e } \\
\text { efetuaram-se de duas formas: na } \\
\text { primeira, ocorria } r \text { o } \\
\text { acompanhamento pelos } \\
\text { monitores, juntamente com os } \\
\text { professores das aulas práticas } \\
\text { da disciplina e, na segunda, os } \\
\text { monitores realizavam as } \\
\text { atividades de orientação aos } \\
\text { alunos que estavam cursando a } \\
\text { disciplina. }\end{array}$ & $\begin{array}{l}\text { Por meio dessa atividade, os monitores } \\
\text { desenvolveram ações de ensino, } \\
\text { pesquisa e extensão que possibilitaram a } \\
\text { consolidação de conhecimentos. }\end{array}$ \\
\hline
\end{tabular}




\section{Atacervo+}

Revista Eletrônica Acervo Saúde | ISSN 2178-2091

\begin{tabular}{|c|c|c|c|c|c|}
\hline № & $\begin{array}{l}\text { Título do Artigo/Autores/Periódico } \\
\text { /Ano de Publicação }\end{array}$ & $\begin{array}{c}\text { Base de } \\
\text { Dados }\end{array}$ & Objetivos & Metodologia / Tipo de Estudo & Conclusão \\
\hline 9 & $\begin{array}{l}\text { Novas possibilidades para o ensino de } \\
\text { enfermagem em saúde mental: uma } \\
\text { experiência de monitoria / Freitas et al. } \\
\text { / Rev Rene / } 2014 \text {. }\end{array}$ & LILACS & $\begin{array}{l}\text { Refletir sobre as possibilidades de } \\
\text { aplicação de novas estratégias } \\
\text { metodológicas no processo de ensino e } \\
\text { aprendizagem em enfermagem. }\end{array}$ & $\begin{array}{l}\text { Pesquisa de Campo: } \\
\text { desenvolvida por meio da } \\
\text { introdução do aluno/monitor nos } \\
\text { conteúdos de aprendizagem } \\
\text { teórico-práticos desempenhados } \\
\text { por meio de Metodologias Ativas } \\
\text { em três semestres acadêmicos } \\
\text { entre } 2010 \text { e 2011, na Faculdade } \\
\text { de Enfermagem da Universidade } \\
\text { Federal do Pará, Brasil. }\end{array}$ & $\begin{array}{l}\text { A monitoria acadêmica desenvolvida no } \\
\text { curso de graduação em enfermagem da } \\
\text { Universidade Federal do Pará trouxe } \\
\text { momentos significativos para a atividade } \\
\text { curricular de saúde mental e psiquiatria. }\end{array}$ \\
\hline 10 & $\begin{array}{l}\text { Percepção dos discentes de } \\
\text { fisioterapia acerca da monitoria } \\
\text { acadêmica / Figueiredo, Filippin e } \\
\text { Vendrusculo / Fisioterapia Brasil / } \\
2016 .\end{array}$ & LILACS & $\begin{array}{l}\text { Conhecer as percepções dos discentes } \\
\text { de fisioterapia acerca da monitoria } \\
\text { acadêmica na formação profissional. }\end{array}$ & Estudo descritivo & $\begin{array}{l}\text { A monitoria acadêmica é aprovada pelos } \\
\text { discentes de fisioterapia entrevistados, } \\
\text { apesar dos pontos negativos } \\
\text { encontrados em seu desenvolvimento, } \\
\text { sendo considerada boa. }\end{array}$ \\
\hline
\end{tabular}

Fonte: Nascimento JT, et al., 2020. 


\section{DISCUSSÃO}

Dentre as atividades que podem ser desenvolvidas pelo discente durante a graduação, a monitoria acadêmica é uma modalidade que engloba o processo ensino-aprendizagem que tem como alguns de seus objetivos a inserção do discente nas atividades extracurriculares disponibilizadas pela instituição, 0 desenvolvimento da comunicação e relacionamento interpessoal tanto com o docente quanto com o discente participante da monitoria e o conhecimento e elaboração de atividades didáticas, contribuindo assim para a melhoria da qualidade do ensino e aprendizado nas instituições de ensino superior (FERNANDES NC, et al., 2015).

Ao atuar como monitor o aluno cria oportunidades, habilidades, competências e se destaca no meio acadêmico devido à quantidade e riqueza dos conhecimentos e experiências adquiridas durante o exercício da monitoria na graduação. Além de estabelecer relações diretas com os alunos e docentes da disciplina, proporcionando também o desenvolvimento de habilidades técnicas, pedagógicas, capacidade de liderar, comunicação e convívio interpessoal (BARBOSA LBM, et al., 2017).

Apesar disto, estudos mostram que apenas $1 \%$ dos alunos que adentram na monitoria possuem algum interesse pela carreira docente em seu futuro profissional, apesar da repercussão que existe a cerca dessa atividade e mesmo à docência não sendo o interesse principal dos discentes, sua prática foi vista positivamente durante o decorrer da monitoria devido a superação das dificuldades pessoais que a monitoria os proporcionou (ABREU TO, et al., 2014).

Figueiredo TC, et al. (2016) enfatizam que é preciso oferecer aos discentes um suporte para que a monitoria funcione de acordo com o que é esperado, pois ela é um importante processo para o desenvolvimento das potencialidades e habilidades necessárias a futura carreira docente. Afinal a monitoria durante a graduação não funciona apenas como um apoio ao estudante, mas também ser porta de entrada para a iniciação e desenvolvimento de várias habilidades ainda desconhecidas pelo discente.

Dessa forma, a monitoria se configura como uma importante atividade realizada durante a graduação para o crescimento pessoal e profissional devido a toda experiência adquirida pelo monitor, consolidando assim todo o conhecimento e aprendizado que Ihe foi proporcionado durante a vida acadêmica (CARVALHO IS, et al., 2012).

De acordo com Fernandes NC, et al. (2015) além de ser uma forma alternativa de trabalho pedagógico a monitoria auxilia como uma ferramenta para solucionar dificuldades na disciplina trabalhada e seu exercício é considerado pelas instituições como um apoio e preparação a formação do discente.

Ao perceber que a atividade de monitoria colabora no processo de formação durante a graduação o discente se coloca como protagonista da sua evolução estudantil e profissional, visando o aproveitamento de todas as oportunidades criadas no decorrer da graduação, a monitoria engloba um espaço de aprendizagem, melhoria de ensino e aperfeiçoamento da carreira acadêmica, pois o monitor passa a assumir uma nova postura e desenvolve novas habilidades e aptidões (FREITAS KFS, et al., 2014).

Segundo Dantas OM (2014) a monitoria acadêmica vem se caracterizado ao longo dos tempos como incentivadora à formação docente por meio das diversas atividades desenvolvidas pelo discente que abrangem teoria, prática, conhecimento teórico e científico, contribuindo para uma formação crítica na graduação e despertando no discente o desejo de especialização nessa área de atuação, tendo em vista que o aluno tende a estudar aquilo que passa a conhecer. Por isso, através da monitoria acadêmica é possível associar o conhecimento técnico a prática clínica de enfermagem, contribuindo para o crescimento e desenvolvimento do discente o que posteriormente acaba tornando o aprendizado e sua experiência curricular mais assertiva.

Tornar-se monitor em Enfermagem exige preparação, atenção, técnica, desenvoltura, liderança, diálogo, força de vontade, método e tempo diferenciados, pois o cuidado de enfermagem é individualizado e demanda muito conhecimento científico, portanto, as implicações da monitoria para o ensino são extremamente importantes para o discente monitor e para o discente que participa das aulas, pois ela contribui diretamente 
no processo de ensino e aprendizagem e em sua formação acadêmica, além de acabar influenciando e incentivando o discente a adentrar à docência superior (FERNANDES NC, et al., 2015).

Nesse contexto, Santos GM e Batista SHSS (2015), afirmam que além da monitoria ser vista como uma ferramenta de auxílio ao processo ensino-aprendizagem e contribuir com o aprendizado e postura metodológica tanto do discente quanto do docente ela é vista pelos alunos como um meio de aprofundar conhecimentos e auxiliar na compreensão da disciplina estudada. $O$ aluno monitor assume nova postura diante de si mesmo, de seus alunos, de seu docente e da sua formação como profissional de enfermagem e passa a ter pensamento crítico a respeito das atividades que estão sendo desenvolvidas por ele em conjunto com o docente.

Desse modo Maran E, et al. (2017) expressa que o monitor através da monitoria consegue romper bloqueios, estabelecer novas percepções, ter reflexões críticas sobre o conhecimento adquirido, tornando-se um mediador e facilitador do aprendizado para os demais discentes, instigando-os acerca do crescimento do pensamento crítico do acadêmico, além de promover a superação de barreiras para o preparo do exercício da docência, mesmo ela não sendo o motivo inicial da sua decisão de se tornar monitor, felizmente ou infelizmente a monitoria foi a forma mais próxima que os estudantes chegaram da prática docente durante a graduação, tendo em vista que também há outras maneiras de abordar a prática docente durante a graduação além das atividades de monitoria.

Mesmo a monitoria permitindo percepções mais abrangentes e o rompimento de barreiras no que tangem processos educacionais e promovendo competência, liderança, habilidade, comunicação, organização e reflexão crítica sobre seu próprio conhecimento, foi constatado que durante a graduação os alunos têm pouco interesse pela docência superior, um dado preocupante já que nas diretrizes curriculares nacionais do curso de graduação em enfermagem, enfatiza-se a importância do desenvolvimento de competências e habilidades como comunicação, tomada de decisões, liderança, administração, gerenciamento e educação permanente ainda durante a graduação, competências estas que são extremamente importantes para o trabalho do enfermeiro não só na assistência hospitalar, mas também na atividade docente e todas elas são proporcionadas através da atividade de monitoria (DANTAS OM, 2014).

A prática da monitoria durante a graduação leva o discente a desenvolver habilidades que ele mesmo não imaginava adquirir acerca da docência, pois a atuação como monitor além de possibilitar uma melhoria na qualidade do ensino-aprendizagem, acaba, por conseguinte ampliando horizontes e desmistificando os saberes pedagógicos e aperfeiçoando também o processo de formação acadêmica, características essas que antes se pensava somente serem possíveis de adquirir durante os programas de pós-graduação (DANTAS OM, 2014).

Essa expansão de conhecimentos acaba permitindo ao monitor uma maior compreensão sobre o papel da docência no ensino superior, a monitoria acabou tomando um espaço de contribuição durante a vida acadêmica, tornando o monitor responsável e consciente acerca da prática educativa que está sendo desenvolvida, o que aumenta seu poder na tomada de decisões, enfrentamento de conflitos, desenvolvimento pedagógico, saberes próprios, planejamento, interação com os demais discentes, experiência em sala de aula e um contato mais realista e próximo com a docência ainda durante a graduação (DANTAS OM, 2014).

Contudo, percebe-se que a monitoria constitui-se em uma ferramenta de suma importância para facilitar o desenvolvimento teórico-prático do aluno, mas não se concretiza como instrumento único e responsável pela qualificação deste, por isso as instituições de ensino superior devem investir nessa prática acadêmica e também em outros meios de capacitação do discente nessa área de atuação do enfermeiro que é a docência, pois ser monitor permite ao discente enxergar uma nova área de atuação além da assistência, oferecendo a este uma visão holística sobre como atuar no âmbito de multiplicador de conhecimento além de introduzi-lo nas formas e métodos didáticos para transferir conhecimento o que é de suma importância para a atuação do enfermeiro na assistência e em diversas áreas (HAAG GS, et al., 2008).

\section{CONSIDERAÇÕES FINAIS}


Para fazer a diferença no que tange à docência em enfermagem, é imprescindível que as instituições de ensino façam valer através da grade curricular do curso de enfermagem o que salienta a Lei das Diretrizes e Bases da Educação Nacional, além de incluir disciplinas voltadas para prática pedagógica e docência no ensino superior. Foi notória a falta de estudos publicados a respeito da temática o que denota a falta de estímulo, vagas, divulgação ou de interesse dos discentes em programas como a monitoria. Ser monitor permite ao discente enxergar uma nova área de atuação além da assistência, oferecendo a este uma visão holística sobre como atuar no âmbito de multiplicador de conhecimento além de introduzi-lo nos métodos didáticos para transferir conhecimento, que é de suma importância para a atuação do enfermeiro na assistência e em diversas áreas.

\section{REFERÊNCIAS}

1. ABREU TO, et al. A Monitoria Acadêmica na Percepção dos Graduandos de Enfermagem. Rev enferm UERJ., 2014; 22(4): 507-12.

2. ANDRADE EGR, et al. Contribution of academic tutoring for the teaching-learning process in Nursing undergraduate studies. Rev Bras Enferm [Internet]. 2018; 71(Suppl 4): 1596-603.

3. BARBOSA LBM, et al. A Monitoria de Educação em Saúde na Enfermagem: relato de experiência. Rev enferm UFPE on line., 2017; 11(Supl. 7): 2979-84.

4. BRASIL. Conselho Nacional De Educação. Câmara de Educação Superior. Resolução CNE/CES 3/2001. Diário Oficial da União, Brasília, 9 de novembro de 2001; 1: 37.

5. BRASIL. Senado Federal. Lei no 9.394, de 20 de dezembro de 1996. Lei de Diretrizes e Bases da Educação Nacional, Brasília, DF, 2005.

6. CARVALHO IS, et al. Monitoria em Semiologia e Semiotécnica para a Enfermagem: um relato de experiência. Rev Enferm UFSM. 2012; 2(2): 464-471.

7. DANTAS OM. Monitoria: Fonte de saberes à docência superior. Rev. bras. Estud. pedagog. (online), Brasília, 2014; 95(241): 567-589.

8. FERNANDES NC, et al. Monitoria Acadêmica e o Cuidado da Pessoa com Estomia: relato de experiência REME, Rev Min Enferm. 2015; 19(2): 238-241.

9. FIOCRUZ. Fundação Oswaldo Cruz. Pesquisa inédita traça perfil da enfermagem no Brasil, Agência Fiocruz de Notícias, 2015.

10. FIGUEIREDO TC, et al. Percepção dos Discentes de Fisioterapia Acerca da Monitoria Acadêmica. Fisioterapia Brasil. $2016 ; 17(5)$ : 450-456.

11. FREITAS KFS, et al. Novas Possibilidades para o Ensino de Enfermagem em Saúde Mental: uma experiência de monitoria. Rev Rene. 2014; 15(5): 898-903.

12. HAAG GS, et al. Contribuições da Monitoria no Processo Ensino-Aprendizagem em Enfermagem. Rev Bras Enferm. 2008; $61(2): 215-20$.

13. LIMA PG, SANTOS PLF. O Professor de Ensino Superior do Curso de Enfermagem no Brasil: Exigências, Identidade e Formação Didático-pedagógica. In: LIMA PG. Docência e formação universitária no Brasil: Desafios e encaminhamentos. Dourados, MS: UFGD, 2016; 73.

14. LIRA MO, et al. Contribuições da Monitoria Acadêmica Para o Processo de Formação Inicial Docente de Licenciados em Ciências Biológicas da UEPB. In: Congresso Nacional de Educação, 2., 2015, Campina Grande, PB. Anais[...]. Paraíba: Editora Realize, 2015.

15. MARAN E, et al. Habilidades e Dificuldades Técnico-Científicas dos Acadêmicos de Enfermagem Durante a Monitoria de Semiotécnica. Rev enferm UFPE. on line., Recife, 2017; 11(5): 1819-25.

16. MENDES KDS, et al. Revisão Integrativa: Método de Pesquisa para a Incorporação de Evidências na Saúde e na Enfermagem. Texto Contexto Enferm. on line., Florianópolis, 2008; 17(4): 758-64.

17. NASCIMENTO F. A Construção da Docência na Universidade: Reflexões e Possibilidades de Desenvolvimento Profissional. In: LIMA PG. Docência e formação universitária no Brasil: Desafios e encaminhamentos. Dourados, MS: UFGD, 2016; 43.

18. SANTOS GM, BATISTA SHSS. Monitoria Acadêmica na Formação em/para a Saúde: desafios e possibilidades no âmbito de um currículo interprofissional em saúde. ABCS Health Sci. 2015; 40(3): 203-207.

19. TREVISO P, COSTA BEP. Percepção de Profissionais da Área da Saúde Sobre a Formação em sua Atividade Docente. Texto Contexto Enferm, Rio Grande do Sul, 2017; 1-9.

20. VICENZI CB, et al. A Monitoria e seu Papel no Desenvolvimento da Formação Acadêmica. Rev. Ciênc. Ext. 2016; 12(3): 88-94. 